\title{
Molecular Docking, ADME Analysis, and Estimation of MM/GBSA Binding-Free Energies of Coumarin Derivatives as Potential Inhibitors of SARS CoV-2 Receptors
}

\author{
Akhilesh Kumar Maurya \\ Department of Applied Sciences, Indian Institute of Information Technology Allahabad, Devghat, Jhalwa, Prayagraj, India, 211012. \\ Nidhi Mishra \\ Department of Applied Sciences, Indian Institute of Information Technology Allahabad, Devghat, Jhalwa, Prayagraj, India, 211012.
}

\section{Research Article}

Keywords: SARS CoV-2, docking, ADME/T, Binding Free energy

Posted Date: April 30th, 2020

DOI: https://doi.org/10.21203/rs.3.rs-25847/v1

License: () (1) This work is licensed under a Creative Commons Attribution 4.0 International License. Read Full License 


\begin{abstract}
Coronavirus Disease (COVID-19) is recently declared pandemic (WHO) caused by Severe Acute Respiratory Syndrome Coronavirus 2 (SARS-CoV-2). Currently, there is no specific drug for the therapy of COVID-19. In the present study, in silico study have been done to find out possible inhibitors of SARS CoV-2. Coumarin derivatives with 2755 compounds were virtually screen against methyltransferasestimulatory factor complex of NSP16 and NSP10, NSP15 Endoribonuclease, ADP ribose phosphatase (ADRP)of NSP3 and protease enzymes of SARS CoV-2. Docked top five compounds showed good docking scores and free energy of binding with the respective receptors. ADME/T analysis of docked compound shows the docked ligands are showing drug-likeness properties.
\end{abstract}

\title{
Introduction
}

Coronaviruses are medically and veterinary important viruses. They have lipoprotein envelopes with single-stranded RNA and enter in host cells with help of class I fusion protein [1]. They include human coronaviruses (SARS-CoV) severe acute respiratory syndrome coronavirus, porcine epidemic diarrhea virus (PEDV), transmissible virus (TGEV), MERS- CoV (Middle East respiratory syndrome coronavirus) [1]. Recently in December-2019, many patients were suffering from unknown pneumonia and dry cough in Wuhan city, Hubei province, China [2], a new coronavirus, named as novel coronavirus-2019 (nCoV-2019) on January 7, 2020, by the World Health Organization (WHO) [2]. Later the virus was renamed Severe Acute Respiratory Syndrome Coronavirus 2 (SARS-CoV-2), COVID-19 (Coronavirus Disease 2019) caused by the SARS-CoV-2. Zoonotic origin of SARS-CoV-2 has been implicated by phylogenetic data analysis [3]. On March 11, 2020, COVID-2019 disease outbreak declared pandemic [4]. According to the latest data, confirmed cases of COVID-2019 disease are 416,686, confirmed deaths 18,589 in 197 countries worldwide [5] and the number of confirmed cases on India reached 593 of which 11 were dead and 43 cured [6].

Currently, we do not have any specific drugs for the treatment of COVID-2019 patients. Some potential combinations of protease inhibitors like lopinavir/ritonavir commonly used in the treatment of HIV and other antiviral inhibitors like remdesivir, tenofovir disoproxil are using for the treatment of COVID-2019 patient [7].

The scientist has designed various antiviral drugs by synthetic methods and nature have thousands of drugs in the form of medicinal plant, fungi, algae and other natural resources. Various plant contains coumarin and its derivatives known as natural coumarins like Rutamarin, Frutinone A, Floroselin obtained from Ruta graveolens, Polygala fruticose, Seseli sessiliflorum respectively [8], etc. Chemically synthesised coumarins are coumarin, 8-nitro-7- hydroxycoumarin [9], 4-formylcoumarin [10], 8-hydroxy-7phenylaminocoumarin [11], etc.

Coumarin derivatives have been used as antiviral agent in various viral disease such as 2-[(6_- bromocoumarin-3_-yl) methylenethio]5-fluorobenzimidazole and its derivative 1-[(2,3,4,6- tetra-O-acetyl) glucopyranos-1-yl] -2-[(6-bromocoumarin-3-yl) methylenethio] benzimidazole as anti-hepatitis C [12], N-benzylated coumarin-AZT conjugates inhibits HIV protease and reverse transcriptase [13], bis(triazolothiadiazinyl coumarin) as anti-influenza agent [14], etc. In the present study, we have done the in silico screening of coumarin derivatives against protease, NSP15 endonuclease, ADP ribose of phosphatase NSP3 and methyltransferase NSP16 of SARS-CoV-2. The outputs of the present study will provide information to other researchers with opportunities to identify the accurate drug to treating COVID-19.

\section{Result And Discussion}

In the present study, methyltransferase, endoribonuclease, ADP ribose phosphatase, and protease were evaluated through molecular docking studies with coumarin derivatives, which is an in silico analysis, using Glide module of Schrodinger.

\section{Virtual Screening and Molecular Docking of Coumarin Derivatives}

Coumarin derivatives (2755 compound) were docked at the active site of methyltransferase (MTase), endoribonuclease(endoU), ADP ribose phosphatase, and protease and top 5 compounds of each have docking score from -9.00 to $-7.97,-8.42$ to $-6.80,-8.63$ to 7.48 and -7.30 to $-6.01 \mathrm{kcal} / \mathrm{mol}$ respectively (Table 1). Closer view of the interaction of ligands and each SAR CoV-2 proteins/receptors discloses that the oxygen and nitrogen-containing compounds of coumarin derivatives are interacting with active site's amino acids of receptors, $\mathrm{H}$ atom of hydroxy groups make coumarin derivatives more suitable to form a hydrogen bond with the target macromolecule and show the good docking score [16] (Figure 1-4 and Table 1).

Page $2 / 11$ 


\section{Estimation of Binding Free Energy}

The calculations of MM/GBSA were performed to estimate the relative binding affinity of ligands to the receptor. The top five compounds of methyltransferase (MTase), endoribonuclease (endoU), ADP ribose phosphatase, and protease binding-free energy values are in table 1. Coumarin derivatives with good docking scores were showed good binding free energy with their respective receptors. So, these coumarin derivatives may be a potent inhibitor of SARS CoV-2.

Table 1: docking score and glide parameters

\begin{tabular}{|c|c|c|c|c|c|c|}
\hline $\begin{array}{l}\mathrm{S} \\
\mathrm{N}\end{array}$ & $\begin{array}{l}\text { PubChem } \\
\text { CID }\end{array}$ & Interacted amino acid & $\begin{array}{l}\text { Gibs binding } \\
\text { free energy }\end{array}$ & \begin{tabular}{|l|} 
Dockin \\
g score
\end{tabular} & \begin{tabular}{|l|} 
Glide \\
emodel \\
\end{tabular} & $\begin{array}{l}\text { Glide } \\
\text { energy }\end{array}$ \\
\hline \multicolumn{7}{|c|}{ Methyltransferase } \\
\hline 1 & 101223868 & A; met248, A; thr48, & -69.61 & -9.00 & -66.68 & -50.41 \\
\hline 2 & 688485 & B; thr48, glu61 & -58.58 & -8.51 & -67.36 & -51.74 \\
\hline 3 & 53393956 & A; gln88, pro252 & -76.74 & -8.27 & -87.18 & -59.73 \\
\hline 4 & 10781960 & A; met248, gln88, B; thr48 & -58.89 & -8.09 & -62.59 & -45.36 \\
\hline 5 & 102214788 & A; gln88, B; glu61 & -60.33 & -7.97 & -60.22 & -39.98 \\
\hline \multicolumn{7}{|c|}{ Endoribonuclease } \\
\hline 1 & 44406281 & A; glu69, lys71, asn200, thr275, tyr279, asp297 & -56.22 & -8.42 & -54.43 & -40.50 \\
\hline 2 & 25128696 & A; lys71, leu201, ser274, thr275, asp297 & -61.82 & -7.69 & -58.90 & -46.17 \\
\hline 3 & 101223868 & A; lys71, ser274, thr275, asp297 & -58.96 & -7.32 & -55.19 & -42.09 \\
\hline 4 & 22203 & A; lys90, asp268, asp 297 & -59.04 & -6.92 & -52.76 & -41.33 \\
\hline 5 & 5362190 & A; lys71, asp273, ser274, asp297 & -54.00 & -6.80 & -53.76 & -37.63 \\
\hline
\end{tabular}

\begin{tabular}{|c|c|c|c|c|c|c|}
\hline 1 & 54730083 & B; ala38, ala50, leu126 & -59.05 & -8.63 & -61.51 & -45.62 \\
\hline 2 & 53393956 & B; lys44, val49, thr71, leu126, ala 129 & -76.32 & -8.22 & -64.09 & -49.41 \\
\hline 3 & 3758198 & B; leu126, phe156 & -72.24 & -7.81 & -58.89 & -44.49 \\
\hline 4 & 88279989 & B; ala50, leu126 & -64.25 & -7.72 & -56.87 & -35.43 \\
\hline 5 & 5359550 & B; leu126, ala154, asp157 & -72.09 & -7.48 & -44.97 & -39.33 \\
\hline \multicolumn{7}{|c|}{ Protease } \\
\hline 1 & 101223868 & A; gln110, ile 246 & -58.67 & -7.30 & -45.27 & -35.70 \\
\hline 2 & 9818076 & A; gln107, pro108, glu140 & -59.83 & -6.33 & -47.59 & -35.43 \\
\hline 3 & 43000 & A; pro108, glu240, hie246 & -43.27 & -6.24 & -36.81 & -29.68 \\
\hline 4 & 11616886 & A; glu240, hie246 & -65.34 & -6.23 & -43.30 & -34.01 \\
\hline 5 & 23618487 & A; glu240 & -63.21 & -6.01 & -40.35 & -32.46 \\
\hline
\end{tabular}

\section{DME/T properties analysis}

In silico pharmacokinetic and pharmacodynamics properties of the coumarin derivatives calculated by the using QikProp utility of Maestro 12.0. The top 5 docked compounds of each enzyme showed the best score. It predicts the drug-likeness feature of ligands. 


\section{Lipinski rule of five}

Pharmacodynamic and pharmacokinetic properties of ligands define drug-likeness of compounds. Lipinski rule defines numbers for some parameters compounds which are molecular weight $<500$, QPlogPo/w $<5$, donorHB $\leq 5, \operatorname{accptHB} \leq 10$. The numbers of parameters are in multiples of 5 , so, this the rule of five. The compounds which satisfy these numbers for the same parameters are considered as the drug-likeness [17]. ADME/T calculation and rule of five of the top 5 compounds of each enzyme are given in table 2.

Methyltransferase of SARS CoV-2 involves mRNA capping and cap by 2'-0-ribose methylation to the 5'-cap structure of viral mRNAs.NSP16 is a binding site of the N7-methyl guanosine cap. So, methyltransferase plays an important role in viral mRNAs cap methylation [18]. EndoU enzyme of all known CoVs is highly conserved $(19,20)$. EndoU enzyme of coronaviruses is similar to the animal cellular endoribonuclease [21]. It plays a role in mRNA maintenances. Adenosine diphosphate ribose phosphatase (ADRP) domain of SARS CoV nsP3 is indeed a phosphatase that removes the terminal 1" phosphate from Appr-1"-p[22]. CoV S (coronavirus spike glycoprotein) proteins are class I viral fusion proteins, and for the fusion with human body cells activation of $S$ protein is required and protease cleavage is required for S protein activation [23]. So, all taken enzymes or receptors very actively participate in the replication and infection of SARS CoV-2 and inhibition of these targets may inhibit the infection of SARS CoV-2 or may cure the infected people with COVID-19. In present in silico study, coumarin derivatives actively interact with taken receptors and showed good docking results for methyltransferase (MTase), endoribonuclease(endoU), ADP ribose phosphatase, and protease and top 5 compounds of each have docking score from -9.00 to $-7.97,-8.42$ to $-6.80,-8.63$ to -7.48 and -7.30 to $-6.01 \mathrm{kcal} / \mathrm{mol}$ respectively. All the enzymes showed good results with different compounds, therefore, less chance to be resistant to other targets. So, the combination therapy of the active compounds may be potent inhibitors of SARS CoV-2.

Table 2: ADME/T properties of top 5 compounds of each enzymes/receptor.

\begin{tabular}{|c|c|c|c|c|c|c|c|c|c|c|c|}
\hline $\begin{array}{ll}\text { S. } \\
\text { N. }\end{array}$ & $\begin{array}{l}\text { PubChem } \\
\text { CID }\end{array}$ & IUPAC Name of compounds & MW & \begin{tabular}{l|l}
$\log$ \\
$\mathrm{S}$
\end{tabular} & Logo/w & $\begin{array}{l}\text { Accpt } \\
\mathrm{H}\end{array}$ & \begin{tabular}{l|l} 
Donor \\
$\mathrm{H}$
\end{tabular} & $\begin{array}{l}\text { QPP } \\
\text { Caco }\end{array}$ & $\begin{array}{l}\text { QPlog } \\
\text { BB }\end{array}$ & $\begin{array}{l}\text { \%Human } \\
\text { OralAbs }\end{array}$ & $\begin{array}{l}\text { QPlog } \\
\text { HERG }\end{array}$ \\
\hline \multicolumn{12}{|c|}{ Methyltransferase } \\
\hline 1 & 101223868 & $\begin{array}{l}\text { 7-[(2S,3S)-2,3,5-trihydroxy-4-oxopentoxy]-1- } \\
\text { benzopyran-2-one }\end{array}$ & 294.26 & \begin{tabular}{|l|}
$\mid-1.66$ \\
\end{tabular} & -0.23 & 9.35 & 2 & 53.38 & -2.18 & 56.48 & -4.89 \\
\hline 2 & 688485 & $\begin{array}{l}\text { (2S)-2-amino-5-[(4-methyl-2-oxo-1- } \\
\text { benzopyran-7-yl)amino]-5-oxopentanoic acid }\end{array}$ & 304.30 & -2.48 & -1.80 & 8 & 4 & 2.00 & -1.95 & 21.78 & -3.94 \\
\hline 3 & 53393956 & $\begin{array}{l}\text { N'-hydroxy-N-(4-methyl-2-oxo-1-benzopyran- } \\
\text { 7-yl) octanediamide }\end{array}$ & 346.38 & \begin{tabular}{|l|} 
\\
\end{tabular} & 0.35 & 9.2 & 3 & 22.28 & -2.74 & 53.13 & -4.47 \\
\hline 4 & 10781960 & $\begin{array}{l}\text { 6-[(4-phenyl-1-piperazinyl) methyl]-1- } \\
\text { benzopyran-2-one }\end{array}$ & 320.39 & -3.27 & 2.90 & 5.5 & 0 & 468.59 & 0.10 & 91.76 & -6.76 \\
\hline 5 & 102214788 & $\begin{array}{l}\text { 3,4,5-trihydroxybenzoic acid (2-oxo-1- } \\
\text { benzopyran-4-yl) ester }\end{array}$ & 314.25 & -2.91 & 0.35 & 7.25 & 3 & 32.92 & -2.17 & 56.18 & -5.33 \\
\hline \multicolumn{12}{|c|}{ Endoribonuclease } \\
\hline 1 & 44406281 & $\begin{array}{l}\text { 3-(3,5-dihydroxyphenyl)-6,8-dihydroxy-1- } \\
\text { benzopyran-2-one }\end{array}$ & 286.24 & -2.70 & 0.31 & 5.5 & 4 & 24.90 & -2.23 & 53.75 & -4.98 \\
\hline 2 & 25128696 & $\begin{array}{l}\text { 4-[(3,4-dihydroxy-2-methoxyphenyl) thio]-1- } \\
\text { benzopyran-2-one }\end{array}$ & 316.32 & \begin{tabular}{|l|} 
\\
\end{tabular} & 2.22 & 4.75 & 2 & 293.75 & -1.12 & 84.15 & -4.99 \\
\hline 3 & 101223868 & $\begin{array}{l}\text { 7-[(2S,3S)-2,3,5-trihydroxy-4-oxopentoxy]-1- } \\
\text { benzopyran-2-one }\end{array}$ & 294.26 & $|-1.66|$ & -0.23 & 9.35 & 2 & 53.38 & -2.18 & 56.48 & -4.89 \\
\hline 4 & 22203 & $\begin{array}{l}\text { 8-[3-(dimethylamino) propoxy]-3-pyridin-4-yl- } \\
\text { 1-benzopyran-2-one }\end{array}$ & 324.37 & -2.67 & 2.46 & 6.75 & 0 & 365.23 & -0.29 & 87.23 & -6.86 \\
\hline 5 & 5362190 & $\begin{array}{l}\text { (6,7-dihydroxy-4-methyl-2-oxo-1- benzopyran- } \\
\text { 8-yl)methyl- } \\
\text { diethylammonium;chloride }\end{array}$ & 277.31 & \begin{tabular}{|l|}
-1.78 \\
\end{tabular} & 1.07 & 6 & 2 & 97.39 & -0.73 & 68.82 & -4.90 \\
\hline \multicolumn{12}{|c|}{ Phosphatase } \\
\hline 1 & 54730083 & $\begin{array}{l}\text { 4-hydroxy-7-(2-hydroxy-3- } \\
\text { phenoxypropoxy)chromen-2-one }\end{array}$ & 328.32 & -3.87 & 2.28 & 6.45 & 2 & 282.91 & -1.59 & 84.20 & -6.49 \\
\hline 2 & 53393956 & $\begin{array}{l}\text { N'-hydroxy-N-(4-methyl-2-oxochromen-7- } \\
\text { yl) octanediamide }\end{array}$ & 346.38 & -2.97 & 0.35 & 9.2 & 3 & 22.28 & -2.74 & 53.13 & -4.47 \\
\hline 3 & 3758198 & $\begin{array}{l}\text { 3-[2-[(4,5-dimethoxy-3-oxo-1H-2-benzofuran- } \\
\text { 1-yl)amino]-1,3-thiazol-4-yl]chromen-2-one }\end{array}$ & 436.43 & -4.85 & 2.85 & 9 & 1 & 605.02 & -0.82 & 93.45 & -5.96 \\
\hline 4 & 88279989 & $\begin{array}{l}\text { 7-[(4-chloro-6-methoxy-1,3,5-triazin-2- } \\
\text { yl) amino]-3-phenylchromen-2-one }\end{array}$ & 380.79 & -5.26 & 3.59 & 6 & 1 & 808.94 & -0.63 & 100 & -6.18 \\
\hline
\end{tabular}




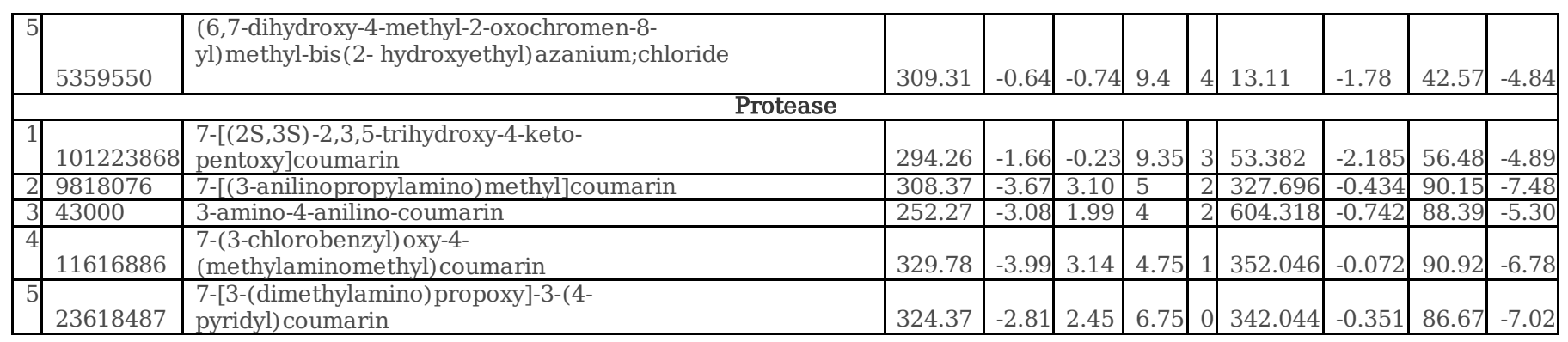

Where,

$\mathrm{MW}=$ Molecular weight

$\log S=$ Predicted aqueous solubility

logo/w = Predicted octanol/water partition coefficient

AccptH = Estimated number of hydrogen bonds that would be accepted by the solute from water molecules in an aqueous solution DonorH = Estimated number of hydrogen bonds that would be donated by the solute to water molecules in an aqueous solution.

QPPCaco $=$ Predicted apparent Caco-2 cell permeability in nm/sec. Caco2 cells are a model for the gut-blood barrier QPlogBB = Predicted brain/blood partition coefficient.

\%HumanOralAbs = Predicted human oral absorption on 0 to $100 \%$ scale QPlog HERG = Predicted IC50 value for blockage of HERG K+ channels

\section{Experimental}

\section{Material and Methods}

The in silico studies were performed on Lenovo ThinkPad which has 12 GB RAM, 1TB hard disk, Intel i7 generation with 6 core. Molecular docking was performed on GLIDE (Grid-based Ligand Docking with Energetics) module of maestro 12.0 (Schrodinger LLC 2019, USA) between ligand/s molecules with a receptor macromolecule, mainly protein.

\section{Ligand Preparation}

Some coumarin derivatives, both naturally derived and chemically derived were found to have good antiviral activity. Based on biological activity 2755 compounds of coumarin derivatives weredownloadedfromthewebsitePubChem

(https://pubchem.ncbi.nlm.nih.gov/\#query = coumarin), is a chemical database in SDF format. These ligands were prepared using the LigPrep module of Maestro. LigPrep performs 3D low energy structure conversion from 2D with accurate chiralities. Ionization were retained in original states with realistic bond lengths and bond angles, tautomers, ring conformation were generated, using the OPLS2005 force field.

\section{Protein Preparation}

The protein structures, namely, 6w61 (methyltransferase-stimulatory factor complex of NSP16 and NSP10), 6vww (NSP15 Endoribonuclease), 6vxs (ADP ribose phosphatase (ADRP) of NSP3) and 6lu7 (protease) were retrieved from protein data bank (https://www.rcsb.org/) as anti-COVID-2019 targets. Retrieved structures were subjected to the protein preparation wizard of Maestro for preparation of the structures. The selected structures were processed for the incorporation of creating zero bond order for metal, assigning proper bond orders, creating disulphide bonds, and the addition of missing hydrogens. Optimization of hydrogen bonds was assigned using sample water orientations and Non-hydrogen atoms of protein structures were energy minimized until the RMSD (root mean square deviation) reaches the value of $0.3 \AA$. 


\section{Generation of Receptor Grid}

Cocrstallized structures downloaded from PDB had ligand was separated. The partial atomic charge cutoff was 0.25 and Van der Waals radii of receptor atoms were $1.0 \AA$ by defaults. The centroid of the workspace ligand has an enclosing box to represent the activity of receptor/s.

Center of the bound ligand in receptor/s was selected to generate a grid box by using the above protocol in the receptor grid generation module of Maestro.

\section{Virtual Screening and Molecular Docking}

Virtual screening of prepared coumarin derivatives was performed using virtual screening workflow (VSW) of GLIDE (maestro, Schrödinger, LLC, New York, NY, USA). Running QuikProp, prefilters by Lipinski rule and remove ligands with reactive function groups were selected in VWS for filtering the ligands. VWS of Glide has three levels of Choose a docking precision, HTVS (High Throughput Virtual Screening) for rapid screening of large number ligands docking, standard-precision (SP) for screening ligands of unknown quality in large numbers, Extra-precision (XP) a more powerful and discriminating procedure for docking and scoring of ligands. Extra precision (XP) docking was performed on coumarin derivatives by keeping parameters of the scaling factor at 0.80 and partial charge cutoff at 0.15 . The binding affinity of docked compounds for the receptors, methyltransferase-stimulatory factor complex of NSP16 and NSP10, NSP15 Endoribonuclease, ADP ribose phosphatase of NSP3 and protease, the active site was calculated from the docking binding energy.

\section{Binding Free Energy calculation}

Binding free energy of receptors and docked ligands were predicted using the Prime MM- GBSA (Molecular Mechanics-Generalized Born Surface Area) approach of Maestro 12.0 which includes the OPLS_2005 molecular mechanics energies, nonpolar term of solvation and VSGB solvent model [15]. Prime MM-GBSA was performed using pose viewer file (generated after docking) of lead molecules to calculate binding free energy. The following descriptors were used to calculate changes in energy upon binding.

MM-GBSA DG bind = Ligand binding free energy, MM-GBSA E complex = complex free energy, MM-GBSA E protein = free energy of the receptor without the ligand, MM-GBSA E Ligand = unbound ligand-free energy.

\section{ADME/T Studies}

Absorption, distribution, metabolism, excretion, and toxicity (ADME/T) properties studies reveal the medication properties of drugs. QuikProp tool in VSW (maestro 12.0) calculated the ADME/T (auxiliary, physicochemical, biochemical, pharmacokinetics, and harmfulness properties) information of ligands

\section{Conclusion}

Methyltransferase (MTase), endoribonuclease(endoU), ADP ribose phosphatase, and protease enzymes are essential for the viability of SARS CoV-2. Some coumarin derivatives exhibit antiviral activity. Therefore, it has been attempted to identify inhibitors of methyltransferase (MTase), endoribonuclease(endoU), ADP ribose phosphatase, and protease enzymes produced by SARS CoV-2 to infect and propagate, by using an in silico virtual screening approach. In which, the molecular docking studies were performed for coumarin derivatives. The study yielded five lead compounds of each receptor which have shown promising results against methyltransferase (MTase), endoribonuclease(endoU), ADP ribose phosphatase, and protease enzymes receptors. Top 5 compounds of each receptor VSW were used for the estimation of MM/GBSA binding-free energies. All resulted compounds are showing good docking scores and binding free energy with all selected receptors. All ligand molecules which are showing the good result, show admissible properties of the ADME/ drug-likeness properties and may be considered as potential drug candidates for prospective research to inhibit SARS COV-2.

\section{Declarations}

Page 6/11 


\section{Acknowledgement}

The authors are grateful to the Ministry of Human Resource Development for funding as seed grant money and Indian Institute of Information Technology Allahabad for providing laboratory support to us.

\section{Disclosure statement}

The authors declare that they have no conflicts of interest and nothing to disclose.

\section{Funding}

This work was supported by Ministry of Human Resource Development.

\section{Author contributions}

Akhilesh Kumar Maurya designed experiments, performed all other experiments and data analysis and prepared the manuscript. Nidhi Mishra guided the study and manuscript preparation.

\section{References}

1. Masters, S. The molecular biology of coronaviruses. Advances in virus research. 66, 193-292 (2006).

2. Huang, C. et al. Clinical features of patients infected with 2019 novel coronavirus in Wuhan, China. The Lancet. 395, 497-506 (2020).

3. Lu, R. et al. Genomic characterisation and epidemiology of 2019 novel coronavirus: implications for virus origins and receptor binding. The Lancet. 395, 565-574 (2020).

4. Coronavirus disease (COVID-19) outbreak. World Health Organization, 2020. https://www.who.int/dg/speeches/detail/who-directorgeneral-s-opening-remarks-at- the-media-briefing-on-covid-19. 11-march-2020.

5. Coronavirus disease (COVID-19) outbreak. World Health Organization, 2020. https://www.who.int/emergencies/diseases/ novelcoronavirus-2019 (accessed march 26, 2020).

6. Ministry of Health and Family Welfare, India, https://www.mohfw.gov.in/ (accessed march 26, 2020).

7. Wang, , Chen, X., Lu, Y., Chen, F., \& Zhang, W. (2020). Clinical characteristics and therapeutic procedure for four cases with 2019 novel coronavirus pneumonia receiving combined Chinese and Western medicine treatment. Bioscience trends.14, 64-68 (2020).

8. Murray, R. D. The naturally occurring coumarins. In Fortschritte der Chemie organischer Naturstoffe/Progress in the Chemistry of Organic Natural Products. Springer, Vienna. 83, 1-619 (2002).

9. Egan, , James, P., Cooke, D., \& O'Kennedy, R. Studies on the cytostatic and cytotoxic effects and mode of action of 8-nitro-7hydroxycoumarin. Cancer letters. 118, 201-211 (1997).

10. Nicolaides, D. N., Fylaktakidou, K. C., Litinas, K. E., \& Hadjipavlou-Litina, D. Synthesis and biological evaluation of some 4(isoxazolinyl or 1, 2, 4-oxadiazolyl) coumarins. Journal of heterocyclic chemistry. 33, 967-971 (1996).

11. Bezergiannidou-Balouctsi, C., Litians, K. E., Malamidou-Xenikaki, E., \& Nicolaides, N. Reactions of 7-(Methoxyimino)-4-methyl-2Hchromene-2, 8 (7H)-dione with Phosphorus Ylides. Synthesis of 2-Substituted 6-Methyl-8H-benzopyrano [7, 8-d] oxazol-8-ones. Liebigs Annalen Der Chemie. 11, 1175-1177 (1993).

12. Hwu, R. et al. Synthesis of new benzimidazole-coumarin conjugates as anti-hepatitis $C$ virus agents. Antiviral research. 77, 157$162(2008)$.

13. Olomola, T. O., Klein, R., Mautsa, N., Sayed, Y., \& Kaye, P. T. Synthesis and evaluation of coumarin derivatives as potential dualaction HIV-1 protease and reverse transcriptase inhibitors. Bioorganic \& medicinal chemistry. 21, 1964-1971 (2013).

14. Pavurala, , Vaarla, K., Kesharwani, R., Naesens, L., Liekens, S., \& Vedula, R. R. Bis coumarinyl bis triazolothiadiazinyl ethane derivatives: Synthesis, antiviral activity evaluation, and molecular docking studies. Synthetic Communications. 48, 1494-1503 (2018).

15. Li, J., Abel, R., Zhu, K., Cao, Y., Zhao, S., \& Friesner, R. A. The VSGB 2.0 model: a next generation energy model for high resolution protein structure modeling. Proteins: Structure, Function, and Bioinformatics. 79, 2794-2812 (2011).

16. Jorgensen, W. L., \& Duffy, E. M. Prediction of drug solubility from structure. Advanced drug delivery reviews. 54,355-366 (2002). 
17. Lipinski, C. A., Lombardo, F., Dominy, B. W., \& Feeney, P. J. Experimental and computational approaches to estimate solubility and permeability in drug discovery and development settings. Advanced drug delivery reviews. 23, 3-25 (1997).

18. Swiss-Model. https://swissmodel.expasy.org/repository/species/2697049. march 26,

19. Deng, X., \& Baker, S. C. An "Old" protein with a new story: coronavirus endoribonuclease is important for evading host antiviral defenses. Virology. 517, 157- 163 (2018).

20. Deng, X. et al. Coronavirus endoribonuclease activity in porcine epidemic diarrhea virus suppresses type I and type III interferon responses. Journal of virology. 93, e02000-18 (2019)..

21. Snijder, E. J. et al. Unique and conserved features of genome and proteome of SARS-coronavirus, an early split-off from the coronavirus group 2 lineage. Journal of molecular biology. 33, 991-1004 (2003).

22. Joseph, J. S. et al. Crystal structure of a monomeric form of severe acute respiratory syndrome coronavirus endonuclease nsp 15 suggests a role for hexamerization as an allosteric switch. Journal of virology. 81, 6700-6708 (2007)

23. Ou, X. et al. Identification of the fusion peptide-containing region in betacoronavirus spike glycoproteins. Virol. $90,5586-5600$ (2016).

\section{Figures}

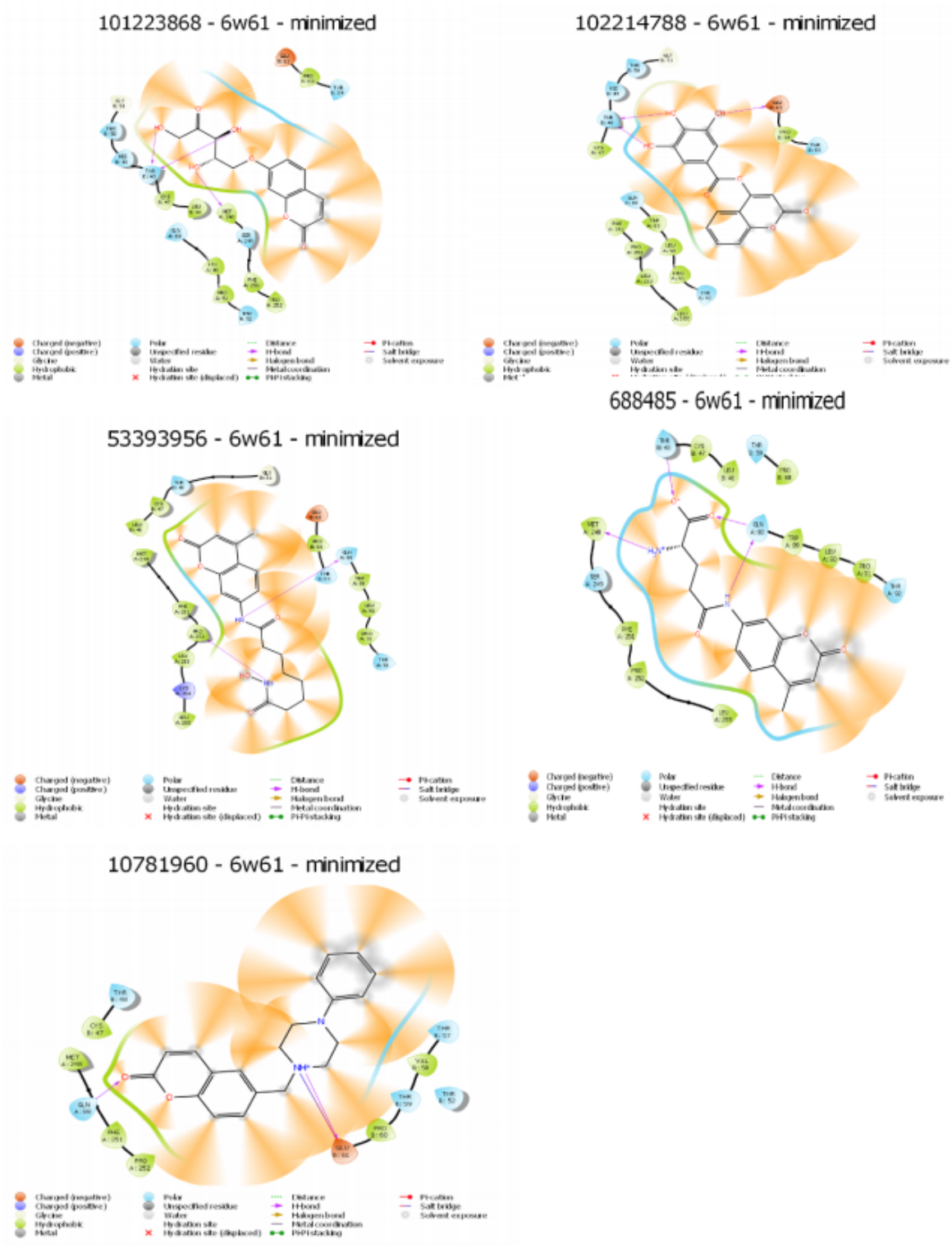

Figure 1

Page 8/11 
Ligand interaction diagram with methyltransferase
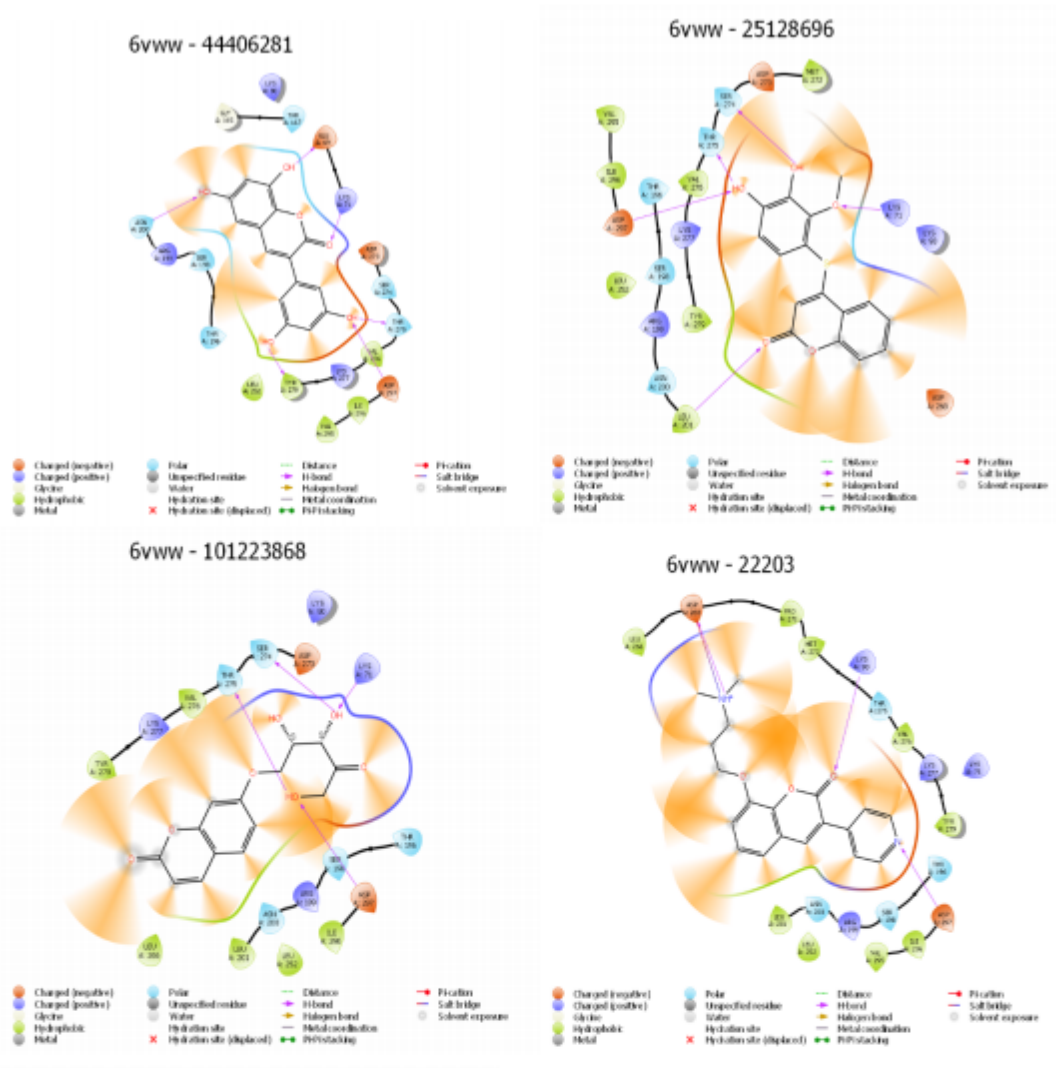
$6 v w w-5362190$
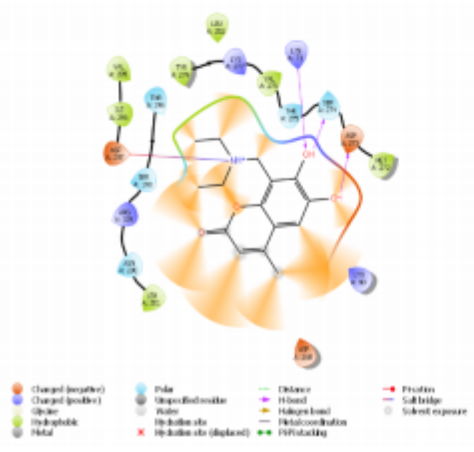

\section{Figure 2}

Ligand interaction diagram with endoribonuclease 


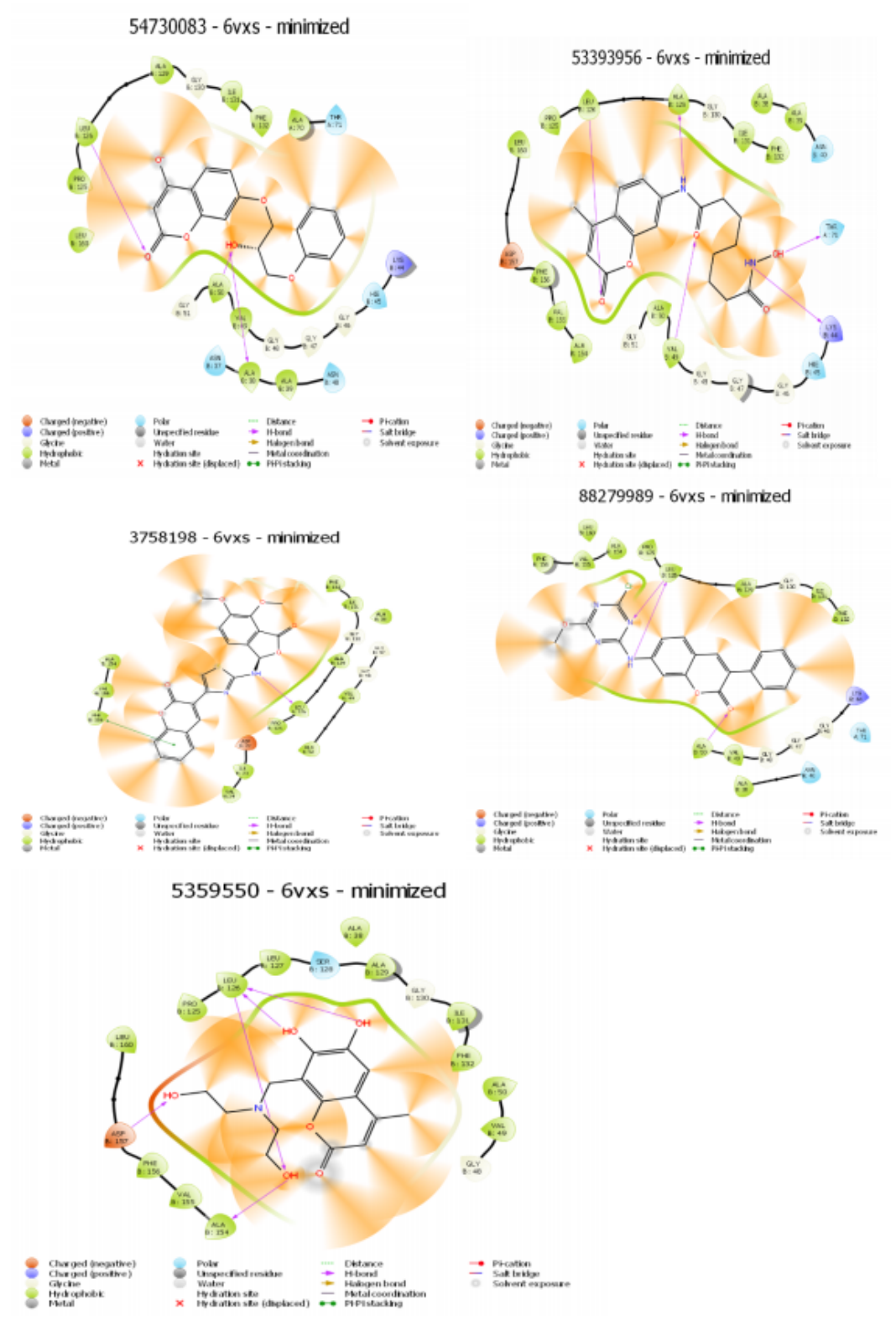

Figure 3

Ligand interaction diagram with phosphatase 


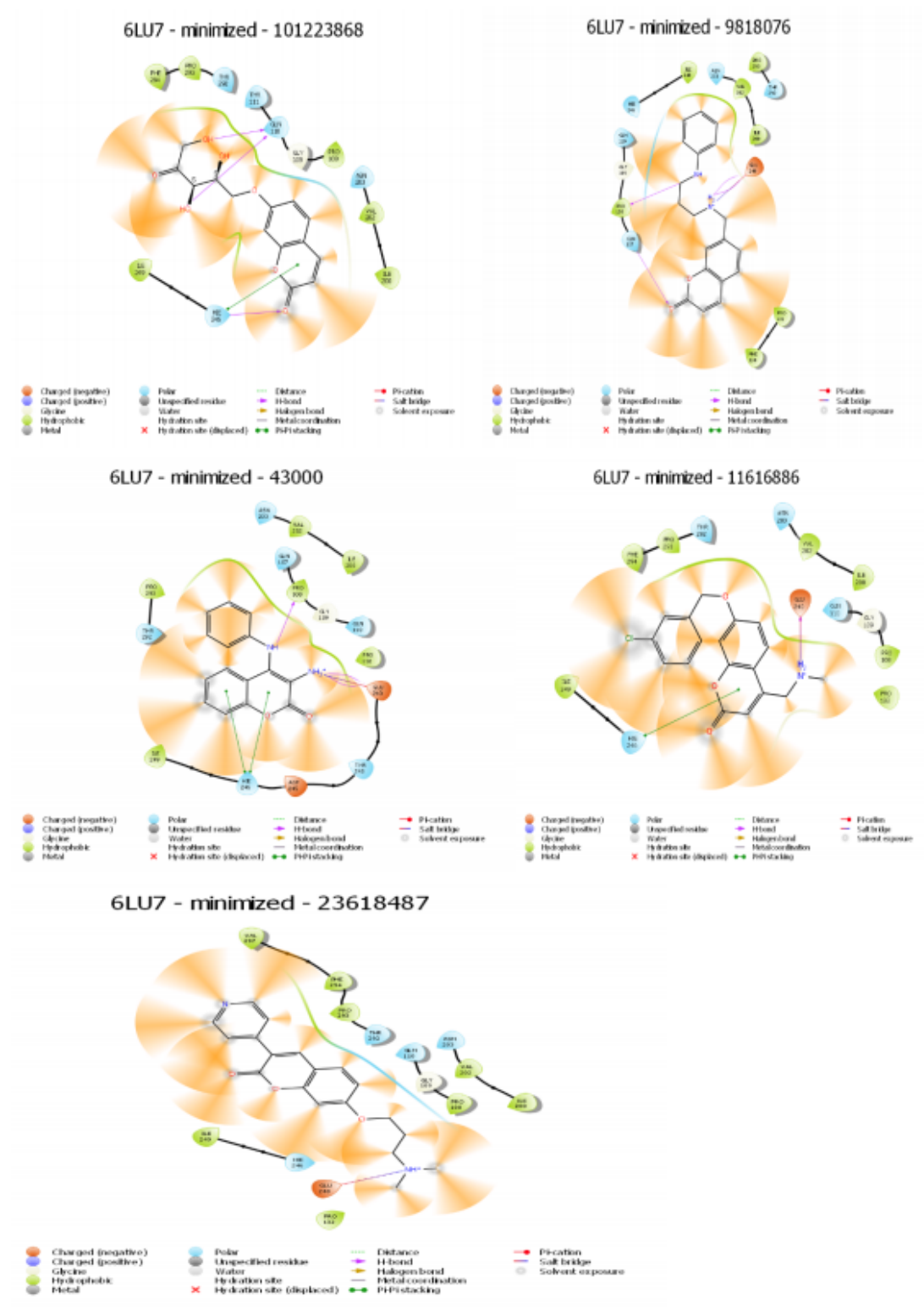

\section{Figure 4}

Ligand interaction diagram with protease

\section{Supplementary Files}

This is a list of supplementary files associated with this preprint. Click to download.

- Supplementalinfo.pdf 